Veloso Mario Enrique (Orcid ID: 0000-0002-9650-9471)

Jansson Pär (Orcid ID: 0000-0002-6729-9428)

De Batist Marc (Orcid ID: 0000-0002-1625-2080)

Minshull Timothy A (Orcid ID: 0000-0002-8202-1379)

Westbrook Graham Karel (Orcid ID: 0000-0002-2260-6033)

Bünz Stefan (Orcid ID: 0000-0002-9215-7325)

Wright Ian Craig (Orcid ID: 0000-0002-6660-0493)

Greinert Jens (Orcid ID: 0000-0001-6186-8573)

\title{
Variability of acoustically evidenced methane bubble emissions offshore western Svalbard
}

\author{
Mario E. Veloso-Alarcón ${ }^{1,2,3}$, Pär Jansson ${ }^{4}$, Marc De Batist ${ }^{2}$, Timothy A. Minshull ${ }^{5}$, \\ Graham K. Westbrook ${ }^{6}$, Heiko Pälike ${ }^{5}$, Stefan Bünz ${ }^{4}$, Ian Wright ${ }^{7}$, Jens Greinert ${ }^{1,2,8}$ \\ ${ }^{1}$ GEOMAR Helmholtz Centre for Ocean Research Kiel, Wischhofstr. 1-3 24148 Kiel, \\ Germany. \\ ${ }^{2}$ Renard Centre of Marine Geology, Ghent University, Krijgslaan 281 s.8 B-9000 Ghent, \\ Belgium. \\ ${ }^{3}$ Universidad Andrés Bello, Facultad de Ingeniería, Calle Quillota 980, Viña del Mar, Chile. \\ ${ }^{4}$ CAGE-Centre for Arctic Gas Hydrate, Environment and Climate, Department of \\ Geosciences, UiT- The Arctic University of Norway, Postboks 6050 Langnes, N-9037 \\ Troms $\varnothing$, Norway.
}

${ }^{5}$ National Oceanography Centre Southampton, University of Southampton, European Way, Southampton SO14 ZH, United Kingdom.

${ }^{6}$ School of Geography, Earth and Environmental Sciences, University of Birmingham, Edgbaston, United Kingdom.

${ }^{7}$ Vice-Chancellor's Office, University of Canterbury, Private Bag 4800, Christchurch, New Zealand.

${ }^{8}$ Christian-Albrechts University Kiel, Institute of Geosciences, Ludewig-Meyn-Str. 10-12, 24098 Kiel, Germany.

Corresponding author: Mario E. Veloso-Alarcón (mveloso@geomar.de)

\section{Key Points:}

- Hydroacoustically derived methane flow-rates from three areas offshore Svalbard range from 725 to $1125 \mathrm{t} \mathrm{CH}_{4} \mathrm{y}^{-1}$.

- Seasonal migration of the landward limit of the methane hydrate stability zone influences locations of bubble seepage.

- Alternating $\mathrm{CH}_{4}$-bubble seepage between two areas suggests geological interconnectivity.

This article has been accepted for publication and undergone full peer review but has not been through the copyediting, typesetting, pagination and proofreading process which may lead to differences between this version and the Version of Record. Please cite this article as doi: 10.1029/2019GL082750

(c) 2019 American Geophysical Union. All rights reserved. 


\begin{abstract}
Large reservoirs of methane present in Arctic marine sediments are susceptible to rapid warming, promoting increasing methane emissions. Gas bubbles in the water-column can be detected and flow-rates can be quantified using hydroacoustic survey methods, making it possible to monitor spatiotemporal variability. We present methane $\left(\mathrm{CH}_{4}\right)$ bubble flow-rates derived from hydroacoustic datasets acquired during 11 research expeditions to the western Svalbard continental margin (2008-2014). Three seepage areas emit in total 725-1125 $\mathrm{t} \mathrm{CH}_{4}$ $\mathrm{y}^{-1}$ and bubble fluxes are up to $2 \mathrm{~kg} \mathrm{~m}^{-2} \mathrm{y}^{-1}$. Bubble fluxes vary between different surveys but no clear trend can be identified. Flux variability analyses suggest that two areas are geologically interconnected, displaying alternating flow changes. Spatial migration of bubble-seepage was observed to follow seasonal changes in the theoretical landward limit of the hydrate stability zone, suggesting that formation/dissociation of shallow hydrates, modulated by bottom water temperatures, influences seafloor bubble release.
\end{abstract}

\title{
Plain Language Summary
}

It has been speculated that the release of methane (a potent greenhouse gas) from the seafloor in some Arctic Ocean regions is triggered by warming seawater. Emissions of gas bubbles from the seafloor can be detected by ship-mounted sonars. In 2008, a methane seepage area west of Svalbard was hydroacoustically detected for the first time. This seepage was hypothesized to be caused by dissociation of hydrates (ice-like crystals consisting of methane and water) due to ocean warming. We present an analysis of sonar data from 11 surveys conducted between 2008 and 2014. This study is the first comparison of methane seepagerelated hydroacoustic data over such a long period.

The hydroacoustic mapping and quantification method allowed us to assess the locations and intensity of gas bubble release, and how these parameters change over time, providing necessary data for numerical flux and climate models. No trend of increasing gas flow was identified. However, we observed seasonal variations potentially controlled by seasonal formation and dissociation of shallow hydrates. The hydrate formation/dissociation process is likely controlled by changes of bottom water temperatures. Alternating gas emissions between two neighboring areas indicate the existence of fluid pathway networks within the sediments.

\section{Introduction}

Underwater methane-bubble emissions are often thought to contribute significantly to global climate change (Hornafius et al., 1999; Kvenvolden, 1993; Shakhova et al., 2010, 2014), but recent evidence has challenged this suggestion. Numerical bubble modeling has shown that, except in water depths shallower than ca. 100 meters below sea level (mbsl), $\mathrm{CH}_{4}$ in bubbles mostly dissolves (McGinnis et al., 2006; Vielstädte et al., 2015) and oxidizes before it reaches the atmosphere/ocean interface (Steinle et al., 2015). Additionally, $\mathrm{CH}_{4}$ seepage may contribute to ocean acidification (Biastoch et al., 2011; Pohlman et al., 2011) and deoxygenation (Boetius \& Wenzhöfer, 2013; Yamamoto et al., 2014). Arctic marine sediments sequester large quantities of $\mathrm{CH}_{4}$ in natural gas deposits, submarine permafrost and gas hydrates (O'Connor et al., 2010; Shakhova et al., 2014). Mechanisms for $\mathrm{CH}_{4}$ release from these reservoirs are poorly constrained but likely comprise hydrate dissociation (Westbrook et al., 2009) triggered by ocean warming and pressure decrease from deglaciation and sea-level change (Andreassen et al., 2017), or submarine permafrost thawing with increased anaerobic organic matter degradation due to ongoing bottom-water warming (James et al., 2016). 
Sediments on the western Svalbard continental margin are influenced by the northward inflow of rapidly warming Atlantic water (AW). Therefore, gas hydrates, if present therein, are more susceptible to dissociation than elsewhere. West of Prins Karls Forland (PKF), a numerous methane seeps were identified in 2008 and this area received additional attention because the seepage was attributed to ocean-warming-induced hydrate destabilization (Westbrook et al., 2009). Other authors have proposed that pressure changes due to isostatic rebound since $8 \mathrm{ka}$ caused hydrate destabilization (Wallmann et al., 2018). The area has been investigated to reveal the gas origin (e.g., Gentz et al., 2014; Sahling et al., 2014), to describe sub-seabed migration mechanisms (e.g., Mau et al., 2017; Rajan et al., 2012; Sarkar et al., 2012), to determine the fate of gas released into the water-column (e.g., Graves et al., 2015; Steinle et al., 2015), to determine the role of anaerobic oxidation in regulating methane flux at the sediment-seawater interface (Graves et al., 2017), to evaluate the warming potential due to $\mathrm{CH}_{4}$ transfer to the atmosphere (e.g., Fisher et al., 2011; Pisso et al., 2016; Pohlman et al., 2017), and to elucidate a possible relationship between bubblerelease and ocean warming (e.g., Berndt et al., 2014; Mau et al., 2017).

Acoustic flares, the hydroacoustic expression of underwater bubble release, were first detected in the area in 2008 (Westbrook et al., 2009) and hydroacoustic evidence of bubbleseepage has been reported repeatedly since (e.g., Berndt et al., 2014; Lund Myhre et al., 2016; Sarkar et al., 2012; Veloso et al., 2015). Our study comprises single-beam echosounder (SBES) data collected during 11 surveys, carried out between 2008 and 2014, by RV Helmer Hanssen (RVHH) and RRS James Clark Ross (RRSJCR). The data allow the first spatiotemporal variability analysis of submarine bubble seepage offshore PKF and first quantitative comparison over several years using hydroacoustic information.

The study area is located west of Svalbard at the shelf offshore PKF (Fig.1), where flares are distributed in three active sub-areas (Fig.1) which we name Slope-Area (upper slope, 300-400 mbsl), SBreak-Area (shelf-break, 200 mbsl), and Shelf-Area (shelf, 90 $\mathrm{mbsl}$ ). Isotope analysis of $\mathrm{CH}_{4}$ collected at the seabed in SBreak-Area and Slope-Area $\left(\delta^{13} \mathrm{C}_{\mathrm{CH} 4}=-55.7 \%\right.$; Mau et al., 2017; Sahling et al., 2014) and in sea surface waters in ShelfArea $\left(\delta^{13} \mathrm{C}_{\mathrm{CH} 4}=-54.6 \%\right.$; Pohlman et al., 2017) suggest a microbial methane origin.

High-resolution seismic data acquired from the SBreak-Area and the Slope-Area suggest that fluids flow upslope along nearly seafloor-parallel permeable layers (Rajan et al., 2012; Sarkar et al., 2012). The main seepage locations may be determined by sediment permeability at the Slope-Area (Sarkar et al., 2012) and by the intersection with the seabed of the latest prograding glacigenic sequence at the SBreak-Area (Rajan et al., 2012). The sediments at the Slope-Area consist of diamictons, coarse ice-rafted debris and hemipelagic material (Bohrmann et al., 2017; Riedel et al., 2018), plausibly causing heterogeneous sediment permeability. Similarly, glacigenic sediments with low permeability were found at a $340 \mathrm{mbsl}$ drilling site, $50 \mathrm{~m}$ above the gas hydrate stability zone (GHSZ), which may inhibit vertical gas migration.

Seepage at the Slope-Area may be a consequence of hydrate dissociation triggered by bottom-water warming since flares are aligned with the landward limit of the gas hydrate stability zone (LGHZ) (Westbrook et al., 2009). Shallow hydrate has been recovered further downslope at 890 mbsl (Fisher et al., 2011), but recent drilling did not recover hydrate near the LGHZ (Riedel et al., 2018). Negative-polarity seismic bright spots have been found at the base of the GHSZ at the Slope-Area may be caused by gas pockets (Sarkar et al., 2012) and/or iceberg scouring (Riedel et al., 2018). Anomalies in seismic velocity (Chabert et al., 2011) and electrical resistivity (Goswami et al., 2016) support the presence of shallow hydrate. 
Seepage at the Shelf-Area has been attributed to hydrate dissociation triggered by ice-sheet unloading after the last deglaciation, with the present-day seepage locations marking previous GHSZ pinch-out locations (Portnov et al., 2016). This hypothesis is supported by similar evidence from the formerly glaciated continental margin of the Barents Sea (Andreassen et al., 2017). Earthquakes related to extension of the nearby spreading ridge system (Fig.1) may influence bubble-seepage indirectly (Plaza-Faverola et al., 2015). Pressure changes due to sea surface height fluctuations could modulate fluxes, as seen elsewhere (Römer et al., 2016).

Two ocean currents control the water properties in the area. The West Spitsbergen Current introduces warm and saline AW from the south; and the Coastal Current contributes fresher and colder Transformed Atlantic Water to the northward flow (Graves et al., 2015; Nilsen et al., 2016). Bottom-water temperature (BWT) changes on seasonal to decadal timescales have been proposed to cause shallow hydrate formation and dissociation in the Slope-Area, yielding a positive correlation between ocean temperature and bubble release (Berndt et al., 2014; Westbrook et al., 2009). However, the hydrate occurrence zone is expected to be thinner than the GHSZ because hydrate formation is limited by the supply of water and $\mathrm{CH}_{4}$ in excess of its solubility, and by the thickness of the sulfate reduction zone (SRZ) in which methane concentrations are too low to allow hydrate formation (Mestdagh et al., 2017; Ruppel \& Kessler, 2017). Shallow hydrate formation may occur within gas conduits, where focused gas advection, overcomes downward sulfate diffusion (Riedel et al., 2018).

Fig.1

\section{Materials and Methods}

\subsection{Hydroacoustic detection of gas venting}

We analyzed hydroacoustic water-column data from 11 surveys conducted during 2008 2014: S1 (08/2008); S2 (07/2009) S3 (10/2010); S4 (07/2011); S5 (08/2011); S6 (07/2012); S7 (07/2012); S8 (07/2013); S9 (10/2013); S10 (06/2014); S11 (10/2014); see supplementary information (SI); Table SI 1. Data were acquired with an EK60 SBES (Kongsberg), which are calibrated routinely, using moving spheres (Foote, 1987), allowing for unbiased comparison of absolute target-strength values (TS; logarithm of ratio between scattered and incident acoustic intensities; $\mathrm{dB}$ re $1 \mathrm{~m}^{2}$ ). We used the $38 \mathrm{kHz}$ frequency for this study because it is common between the two vessels and provided the best backscattering response of bubbles, with the highest signal-to-noise ratio at depths relevant to the study area (Fig. SI 1). We identified 3145 acoustic flares (Fig. SI 2) and selected flares that could be traced clearly from the seabed and were well above (10 dB TS) the background noise of $\sim-70$ dB-TS. For each selected flare, we extracted a representative TS value from a layer 5-10 m above seafloor, using the FlareHunter graphical user interface (FH-GUI;

http://www.geomar.de/en/research/fb2/fb2-mg/deepsea-monitoring/software/flarehunter-andfluxmodule/). Georeferenced footprint areas of the flares and their corresponding centers were obtained from the motion-compensated beam coverage, projected at the layer average depth (SI 1). Subsequently, $\mathrm{CH}_{4}$ flow rates (volume per time unit) for individual flares were calculated, using the inverse hydroacoustic method embedded in the FH-GUI (Veloso et al., 2015, 2019). A bubble size distribution (BSD) was derived from video observations conducted made cruises S2 and S3, as seen in SI 2 and Fig. SI 4 (McGovern, 2012; Veloso et al., 2015). Various bubble rising speed models (BRSM's) for "clean" and "dirty" bubbles (Leifer et al., 2000; Leifer \& Patro, 2002; Mendelson, 1967; Woolf, 1993; Woolf \& Thorpe, 1991), which are all included in the FH-GUI, were used (SI 3 and Fig. SI 5). Ambient water 
properties, gas and environmental constants used for $\mathrm{CH}_{4}$ flow rate quantification are specified in Table SI 2.

\subsection{Areal flow-rates}

Areal flow-rates were calculated for the three areas by integrating over all surveys. Flares were clustered if their footprints overlapped, to avoid overestimating flow rates if vent clusters where insonified repeatedly. Equivalent cluster fluxes were calculated by averaging the individual fluxes (flare flow-rates normalized by their respective virtual footprint-area) of flares within a cluster. Cluster flow-rates were derived by multiplying the cluster-fluxes by the cluster-areas (Veloso et al., 2015; SI 4). Finally, areal flow rates were derived by summation of cluster flow-rates and isolated flare flow-rates (no overlap with other flares) for the three sub-areas individually (Table 1).

Table 1.

\subsection{Temporal flux variation}

Each acoustic dataset results in a unique insonified area. Even if the tracks of multiple surveys are identical, the insonified areas at the seafloor will very likely not be identical, due to vessel motion. Therefore, flow rates derived from different surveys cannot be directly compared. Such a temporal analysis would inevitably suffer from spatial biases. However, bubble fluxes can be used for variability analysis. We developed a common area flux (CAF) method (SI 5) based on the comparison of fluxes from bubbling areas that were repeatedly insonified (including clustered and isolated flares, and their respective flux values). The method follows the technique described in section 2.2, but only flares from the same survey are clustered. The georeferenced flare and cluster areas were gridded on a regular survey matrix with flux values for each cell. A common bubbling area was extracted from the survey matrices (Fig. SI 9) and a representative flux $\left(Q_{R F}\right)$ was calculated, using the arithmetic mean of fluxes in the common area (Fig. 2a).

No flare-related grid cell was covered by all 11 surveys but small areas were covered by up to eight surveys. Our analysis includes multiple combinations of survey matrices with a minimum of two overlapping surveys for the SBreak and Slope-Area (Fig. 1). Several $Q_{R F} \mathrm{~S}$ were obtained for each survey from different combinations of surveys (Tables SI 3 and SI 4), and the average $Q_{R F}$ of each survey $\left(\bar{Q}_{R F}\right)$, is shown in Fig. 2a. The Shelf-Area was not included in this analysis since it was only surveyed once. Since flux magnitudes and their changes are similar when using different "clean" and "dirty" BRSMs, we only show the results for clean bubbles using the 'Leifer' rising speed model (Leifer et al., 2015).

\subsection{Bottom water temperature and evolution of LGHZ}

Mean bottom water temperatures (BWTs) from the SBreak-Area and Slope-Area were extracted from CTD data collected during the surveys and from the World Ocean Database (SI, Excel file). Additionally, we created a synthetic BWT function (Text SI 8) based on MASOX observatory data (Berndt et al., 2014) and a $0.05{ }^{\circ} \mathrm{C}$ yearly BWT increase observed by Ferré et al., (2012). Mean BWTs from CTD casts and values from the synthetic BWT function showed good correlation ( $\rho=0.84$; Fig. 2 b). From the synthetic BWT series, we calculated the expected depth of the LGHZ using the formulae suggested by Tishchenko et al., (2005). This depth is presented together with observed flare depths (FDs) and mean flare depths (MFDs) for each survey (Fig. 2c). Flares located within the Slope-Area and at 350$400 \mathrm{mbsl}$ were included in this comparison. 


\subsection{Hydroacoustic data confidence related to spatial analysis of flares}

We defined two parameters to assess the confidence of the SBES data, relating to spatial seepage migration: a) the relative areal coverage of the SBES-footprint $\left(R_{A C}\right)$, representing the area covered by the SBES-footprint relative to the total analyzed area; and $b$ ) the Complement of the relative quadratic deviation of the SBES-depth distribution $\left(C_{R C D}\right)$, representing the similarity between the SBES-mapped depth distribution and the depth distribution (bathymetry histogram) of the region. Both values were calculated for each survey within a band delimited by the 350 and $400 \mathrm{~m}$ isobaths at the Slope-Area (Fig. 2c) as presented in SI 9.

Fig.2.

\section{Discussion}

\subsection{Quantifying bubble-emissions}

Assuming continuous release of pure $\mathrm{CH}_{4}$ bubbles, we estimate yearly emissions of 210-330, 400-630, and 115-180 tons for the SBreak, Slope, and Shelf Area, respectively. These results are similar to $\mathrm{CH}_{4}$ seepage areas elsewhere (Römer et al., 2014; Römer, Sahling, Pape, Bahr, et al., 2012; Römer, Sahling, Pape, Bohrmann, et al., 2012; Sauter et al., 2006; Schneider von Deimling et al., 2011; Torres et al., 2002) as seen in Table SI 5. Previously obtained flow rates from a sub-section of the SBreak-Area using the same hydroacoustic method (Veloso et al., 2015, 2019), are half of the values presented here. This difference can be attributed to the difference in SBES areal coverage. The risk of missing bubbling areas is reduced by increasing the SBES coverage. Therefore, flow-rates derived from our larger dataset (merging of 9 surveys) is likely a better estimate for the SBreak-Area $\left(\sim 210-330 \mathrm{t} \mathrm{CH}_{4} \mathrm{y}^{-1}\right.$ from $\left.\sim 13.4 \mathrm{~km}^{2}\right)$ than those determined by Veloso et al. (2015) who used only two surveys. Variations can also be introduced by inaccurate flare locations, resulting in flow rate overestimation if the same flare is considered multiple times. The transient nature of bubble release generates another uncertainty since short-term variability is neglected when data from different surveys are combined.

A survey offshore PKF combining multibeam echosounder (MBES) and a ROVbased visual inspection (Sahling et al., 2014) suggested that 433 and $417 \mathrm{t} \mathrm{CH}_{4} \mathrm{y}^{-1}$ are emitted from areas comparable to SBreak-Area and Slope-Area, respectively. This is 0.7-1.3 times our estimates $\left(\sim 290\right.$ and $\left.\sim 550 \mathrm{t} \mathrm{CH}_{4} \mathrm{y}^{-1}\right)$, which indicates remarkably good agreement from different methods by different research teams in the same area, given the uncertainties in both methods. While flow rates calculated from optical methods are more precise than those derived from SBES data inversion, uncertainties arise when extrapolating flow rates from a few visual observations to a larger number of MBES-detected flares. SBES-data inversion may decrease these uncertainties by using the backscatter heterogeneity of all detected flares to derive flow rates, but incorporates other uncertainties inherent in the backscattering model, the BRSMs, the BSDs, and limited SBES footprint coverage compared to MBES (Veloso et al., 2015). Future surveys should consider using a combination of both methods to improve flow rate assessment for large seepage areas.

\subsection{Seepage variability}

Our results show that CAF values in SBreak-Area vary between 0.5 and $2 \mathrm{~kg} \mathrm{CH}_{4} \mathrm{~m}^{-2}$ $\mathrm{y}^{-1}$ with a standard deviation of $0.15-0.35 \mathrm{~kg} \mathrm{CH}_{4} \mathrm{~m}^{-2} \mathrm{y}^{-1}$ (Fig. 2a), indicating that common areas have similar gas emissions over several surveys. Fluxes fluctuate around a mean of 0.75 $\mathrm{kg} \mathrm{CH}_{4} \mathrm{~m}^{-2} \mathrm{y}^{-1}$, except during S2 and S9, when higher fluxes $\left(\sim 1.9\right.$ and $\sim 1.8 \mathrm{~kg} \mathrm{CH}_{4} \mathrm{~m}^{-2} \mathrm{y}^{-1}$, 
respectively) were observed. In the Slope-Area, fluxes ranged from 0.09 to $1.4 \mathrm{~kg} \mathrm{CH}_{4} \mathrm{~m}^{-2} \mathrm{y}^{-1}$ with a mean of $\sim 0.4 \mathrm{~kg} \mathrm{CH}_{4} \mathrm{~m}^{-2} \mathrm{y}^{-1}$. A peak flux was observed for survey $\mathrm{S} 4$, with a standard deviation of $\sim 1.16 \mathrm{~kg} \mathrm{CH}_{4} \mathrm{~m}^{-2} \mathrm{y}^{-1}$, which is perhaps high due to spatial separation of the common areas involved in the mean $Q_{R F}$ calculation. All other mean $Q_{R F}$ values exhibit lower standard deviations $\left(<0.35 \mathrm{~kg} \mathrm{CH}_{4} \mathrm{~m}^{-2} \mathrm{y}^{-1}\right)$.

No clear increase in both bubble seepage and BWT over the investigation time is evident (Figs. 2a, 2b). However, the empirical BWTs are well correlated with values from the predictive BWT function, which includes a yearly rising trend. Long term BWT monitoring with better temporal resolution would be required to rigorously assess bottom-water warming. Increasing BWTs coincide with increased fluxes at the Slope-Area, except for the period between surveys S3 and S4. We tentatively attribute this observation to shallow hydrate formation/dissociation due to BWT fluctuations, although available data limit documentation of this mechanism. Gas seepage may be controlled also by hydrostatic pressure changes (e.g., Schneider von Deimling et al., 2011) and tectonic activity since the area is close $(\sim 40-50 \mathrm{~km})$ to the tectonically active Molloy-Knipovich ridge system and the Hornsund Fault zone (Mau et al., 2017; Plaza-Faverola et al., 2015). We analyzed the relationship between seepage activity, tidally induced pressure changes (SI 6) and earthquake activity in the region (SI 7). Because we lack continuous hydroacoustic records, we were unable to tie seepage variability to these two trigger mechanisms.

\subsection{Seepage migration at the LGHZ}

A seasonal BWT-driven lateral LGHZ shift of approximately $2 \mathrm{~km}$ at the Slope-Area was predicted between summer 2011 and winter 2012 (Berndt et al., 2014) and geothermal modeling of the GHSZ suggests that only the upper $6 \mathrm{~m}$ of sediments is affected significantly by seasonal fluctuations at the Slope-Area within the time frame of this study (Riedel et al., 2018). In order to verify whether a seasonal shift of the LGHZ drives migration of bubble seepage, MFDs were compared to the predicted LGHZ depth (Fig. 2c). The comparison revealed a correlation coefficient of 0.48 . MFDs from four surveys (S2, S4, S7, S8) out of nine show excellent agreement with the predicted depths of the LGHZ (Fig. 2c), which supports the hypothesis of spatial seepage migration driven by BWT modulation.

Nevertheless, we recognize that our data have insufficient temporal resolution of BWT and SBES data, and SBES coverage, as seen in the data confidence (Fig.2d). Hence, the observed relationship between bubble stream locations and the predicted LGHZ awaits confirmation in future studies. From the observed flares, $70 \%$ occur at depths shallower than the predicted LGHZ (Fig. 2d), consistent with blockage of vertical gas migration pathways in the area by shallow hydrates.

\subsection{Sub-seafloor fluid network}

Fluxes at the SBreak-Area are weakly anti-correlated with fluxes in the Slope-Area, except for surveys S8 and S9 as seen in Fig. 2a. Although the correlation is low $(r=-0.22)$, the alternating $\mathrm{CH}_{4}$ bubble seepage suggests connectivity between the two areas through a common sub-seafloor fluid migration system. Flux alternation between the two areas may be caused by transient hydrate formation and dissociation that blocks and opens gas conduits feeding the upslope seepage areas. When vertical pathways are open in the Slope-area, less gas will be supplied to the SBreak-Area. Alternatively, the observed alternating flux could be a result of changing resistance/capacitance of fluid migration pathways due to tectonic activity. 


\subsection{Conceptual model}

We propose that temporal, spatial and quantitative variations of bubble seepage are controlled by a combination of factors: shallow hydrate formation and dissociation due to seasonality; heterogeneity of sediment permeability; hydrostatic pressure changes; and earthquakes. Available observations suggest that seepage in the Slope-Area is influenced by rapid formation and dissociation of hydrates in shallow sediments containing permeable beds and sub-vertical fractures, but other factors also may be involved. The temperature control mechanism can be described as follows (Fig. 2d). If focused gas advection overcomes downward sulfate diffusion, shallow hydrate formation could be possible. Seasonal BWT variations of $\sim 1.5^{\circ} \mathrm{C}$ may affect stability of this shallow hydrate. Gas conduits within the affected zone could partially or completely open due to hydrate dissociation in warm conditions and seal again by hydrate formation during cold conditions. Open conduits may allow vertical migration of $\mathrm{CH}_{4}$ from deeper hydrocarbon reservoirs towards the seafloor, while blocked conduits could force lateral migration. Spatial migration of $\mathrm{CH}_{4}$ seepage therefore takes place due to permeability changes (partial or complete blocking) of the fluid conduit system. Under the assumption of interconnectivity between areas, seasonal hydrates at the Slope-Area may force $\mathrm{CH}_{4}$ to migrate upslope, which increases gas emission in the SBreak-Area. Conversely, seasonal dissociation could release gas earlier along the lateral migration pathways, closer to the Slope-Area, and consequently decrease fluxes at the SBreak-Area.

\section{Conclusions}

Analyses of hydroacoustic data from 11 surveys offshore PKF during 2008-2014 showed no significant trend towards increased seepage. Assuming steady gas flow, the total average $\mathrm{CH}_{4}$ free gas fluxes were $0.75 \mathrm{~kg} \mathrm{CH}_{4} \mathrm{~m}^{-2} \mathrm{y}^{-1}$ at the Shelf break and $0.38 \mathrm{~kg} \mathrm{CH}_{4} \mathrm{~m}^{-2}$ $\mathrm{y}^{-1}$ close to the LGHZ. These fluxes average over short natural fluctuations (days to weeks), and may contribute to future modeling of $\mathrm{CH}_{4}$ budgets in the Arctic Ocean. However, care must be taken when extrapolating over longer periods because we lack data between November and May. Variations in gas fluxes can be linked to warming and cooling of BWT at the Slope-Area. In our study, the majority (70\%) of the observed flares occur at depths shallower than the BWT-controlled LGHZ. Additionally, a correlation was observed between observed MFDs and the predicted depth of the LGHZ. These observations support the hypothesis of temperature-controlled hydrate build-up within the shallow sediments, which modulates both the amount and distribution of gas seepage. The inferred interconnectivity between seepage areas supports the interpretation that seepage is controlled by flow-focusing migration pathways (Rajan et al., 2012; Sarkar et al., 2012), consistent with the proposed seasonal formation and dissociation of shallow hydrates. Our model may be further validated using data of higher spatial and temporal resolution. Since our data were acquired from moving vessels, the echosounder beam only intermittently covered the same seepages. Therefore, we cannot assess the impact on gas seepage intensity of changing seafloor pressure or earthquake activity.

Our data analysis shows that ship-based hydroacoustic methods are an efficient tool for repeated monitoring of bubble release. Applied in a standardized way they will help to establish the response of gas-rich sediments to internal and external forcing mechanisms in the Arctic and elsewhere. Increasing water temperatures are likely to have a long-term impact on gas release and seep distribution offshore PKF. For a more conclusive study, longduration observations are required. 


\section{Acknowledgments and Data}

We thank the crewmembers of RV Helmer Hanssen (UiT the Arctic University of Norway, N-9037 Troms $\varnothing$ ) and RRS James Clark Ross (British Antarctic Survey) for support. MV and JG both received support via COST Action ES0902 (PERGAMON) to join research cruises and acquire data. MV thanks the ERASMUS Mundus program of the EU (grant VECCEU) and the BECAS CHILE: CONICYT PAI/INDUSTRIA 79090016" program of the Chilean government. PJ was supported by the Centre of Excellence: Arctic Gas Hydrate, Environment and Climate (CAGE) funded by the Norwegian Research Council (grant no. 223259). TAM was supported by a Royal Society Wolfson Research Merit award. Data acquisition on RRS James Clark Ross was supported by Natural Environment Research Council grants NE/D005728, NE/H002732/1 and NE/H022260/1. We thank Joana Beja De Almeida E Silva for giving us technical support with data supplied by the National Oceanography Centre. We finally thank the reviewers for their valuable feedback towards improving our manuscript. EK60 data are available at PANGAEA (https://doi.org/10.1594/PANGAEA.902832). This is publication 45 of the Deep Sea Monitoring Group at GEOMAR.

\section{References}

Berndt, C., Feseker, T., Treude, T., Krastel, S., Liebetrau, V., Niemann, H., et al. (2014). Temporal Constraints on Hydrate-Controlled Methane Seepage off Svalbard. Science, 343(6168), 284-287. https://doi.org/10.1126/science.1246298

Biastoch, A., Treude, T., Rüpke, L. H., Riebesell, U., Roth, C., Burwicz, E. B., et al. (2011). Rising Arctic Ocean temperatures cause gas hydrate destabilization and ocean acidification. Geophysical Research Letters, 38(8), L08602. https://doi.org/10.1029/2011GL047222

Boetius, A., \& Wenzhöfer, F. (2013). Seafloor oxygen consumption fuelled by methane from cold seeps. Nature Geoscience, 6(9), 725-734. https://doi.org/10.1038/ngeo1926

Fisher, R. E., Sriskantharajah, S., Lowry, D., Lanoisellé, M., Fowler, C. M. R., James, R. H., et al. (2011). Arctic methane sources: Isotopic evidence for atmospheric inputs. Geophysical Research Letters, 38(21), L21803. https://doi.org/10.1029/2011GL049319

Gentz, T., Damm, E., Schneider von Deimling, J., Mau, S., McGinnis, D. F., \& Schlüter, M. (2014). A water column study of methane around gas flares located at the West Spitsbergen continental margin. Continental Shelf Research, 72, 107-118. https://doi.org/10.1016/j.csr.2013.07.013

Graves, C. A., Steinle, L., Rehder, G., Niemann, H., Connelly, D. P., Lowry, D., et al. (2015). Fluxes and fate of dissolved methane released at the seafloor at the landward limit of the gas hydrate stability zone offshore western Svalbard. Journal of Geophysical Research: Oceans, 120(9), 6185-6201. https://doi.org/10.1002/2015JC011084

Graves, C. A., James, R. H., Sapart, C. J., Stott, A. W., Wright, I. C., Berndt, C., et al. (2017). Methane in shallow subsurface sediments at the landward limit of the gas hydrate stability zone offshore western Svalbard. Geochimica et Cosmochimica Acta, 198, 419-438. https://doi.org/10.1016/j.gca.2016.11.015

Hornafius, J. S., Quigley, D., \& Luyendyk, B. P. (1999). The world's most spectacular marine hydrocarbon seeps (Coal Oil Point, Santa Barbara Channel, California): Quantification of emissions. Journal of Geophysical Research: Oceans, 104(C9), 20703-20711. https://doi.org/10.1029/1999JC900148 
James, R. H., Bousquet, P., Bussmann, I., Haeckel, M., Kipfer, R., Leifer, I., et al. (2016). Effects of climate change on methane emissions from seafloor sediments in the Arctic Ocean: A review. Limnology and Oceanography, n/a-n/a. https://doi.org/10.1002/1no.10307

Kvenvolden, K. A. (1993). Gas hydrates-geological perspective and global change. Reviews of Geophysics, 31(2), 173-187.

Lund Myhre, C., Ferré, B., Platt, S. M., Silyakova, A., Hermansen, O., Allen, G., et al. (2016). Extensive release of methane from Arctic seabed west of Svalbard during summer 2014 does not influence the atmosphere. Geophysical Research Letters, 2016GL068999. https://doi.org/10.1002/2016GL068999

Mau, S., Römer, M., Torres, M. E., Bussmann, I., Pape, T., Damm, E., et al. (2017). Widespread methane seepage along the continental margin off Svalbard - from Bjørnøya to Kongsfjorden. Scientific Reports, 7, 42997. https://doi.org/10.1038/srep42997

McGinnis, D. F., Greinert, J., Artemov, Y., Beaubien, S. E., \& Wüest, A. (2006). Fate of rising methane bubbles in stratified waters: How much methane reaches the atmosphere? Journal of Geophysical Research: Oceans, 111(C9), C09007. https://doi.org/10.1029/2005JC003183

O’Connor, F. M., Boucher, O., Gedney, N., Jones, C. D., Folberth, G. A., Coppell, R., et al. (2010). Possible role of wetlands, permafrost, and methane hydrates in the methane cycle under future climate change: A review. Reviews of Geophysics, 48(4), RG4005. https://doi.org/10.1029/2010RG000326

Pisso, I., Myhre, C. L., Platt, S. M., Eckhardt, S., Hermansen, O., Schmidbauer, N., et al. (2016). Constraints on oceanic methane emissions west of Svalbard from atmospheric in situ measurements and Lagrangian transport modeling. Journal of Geophysical Research. Atmospheres, 121(23), 14188-14200. https://doi.org/10.1002/2016JD025590

Pohlman, J. W., Bauer, J. E., Waite, W. F., Osburn, C. L., \& Chapman, N. R. (2011). Methane hydrate-bearing seeps as a source of aged dissolved organic carbon to the oceans. Nature Geoscience, 4(1), 37-41. https://doi.org/10.1038/ngeo1016

Pohlman, J. W., Greinert, J., Ruppel, C., Silyakova, A., Vielstädte, L., Casso, M., et al. (2017). Enhanced CO2 uptake at a shallow Arctic Ocean seep field overwhelms the positive warming potential of emitted methane. Proceedings of the National Academy of Sciences, 114(21), 5355-5360. https://doi.org/10.1073/pnas.1618926114

Rajan, A., Mienert, J., \& Bünz, S. (2012). Acoustic evidence for a gas migration and release system in Arctic glaciated continental margins offshore NW-Svalbard. Marine and Petroleum Geology, 32(1), 36-49. https://doi.org/10.1016/j.marpetgeo.2011.12.008

Sahling, H., Römer, M., Pape, T., Bergès, B., dos Santos Fereirra, C., Boelmann, J., et al. (2014). Gas emissions at the continental margin west of Svalbard: mapping, sampling, and quantification. Biogeosciences, 11(21), 6029-6046. https://doi.org/10.5194/bg11-6029-2014

Sarkar, S., Berndt, C., Minshull, T. A., Westbrook, G. K., Klaeschen, D., Masson, D. G., et al. (2012). Seismic evidence for shallow gas-escape features associated with a retreating gas hydrate zone offshore west Svalbard. Journal of Geophysical Research: Solid Earth, 117(B9), B09102. https://doi.org/10.1029/2011JB009126 
Shakhova, N., Semiletov, I., Salyuk, A., Yusupov, V., Kosmach, D., \& Gustafsson, Ö. (2010). Extensive Methane Venting to the Atmosphere from Sediments of the East Siberian Arctic Shelf. Science, 327(5970), 1246-1250. https://doi.org/10.1126/science.1182221

Shakhova, N., Semiletov, I., Leifer, I., Sergienko, V., Salyuk, A., Kosmach, D., et al. (2014). Ebullition and storm-induced methane release from the East Siberian Arctic Shelf. Nature Geoscience, 7(1), 64-70. https://doi.org/10.1038/ngeo2007

Steinle, L., Graves, C. A., Treude, T., Ferré, B., Biastoch, A., Bussmann, I., et al. (2015). Water column methanotrophy controlled by a rapid oceanographic switch. Nature Geoscience, 8(5), 378-382. https://doi.org/10.1038/ngeo2420

Veloso, M., Greinert, J., Mienert, J., \& De Batist, M. (2015). A new methodology for quantifying bubble flow rates in deep water using splitbeam echosounders: Examples from the Arctic offshore NW-Svalbard: Quantifying bubble flow rates in deep water. Limnology and Oceanography: Methods, 13(6), 267-287. https://doi.org/10.1002/lom3.10024

Vielstädte, L., Karstens, J., Haeckel, M., Schmidt, M., Linke, P., Reimann, S., et al. (2015). Quantification of methane emissions at abandoned gas wells in the Central North Sea. Marine and Petroleum Geology, 68, Part B, 848-860. https://doi.org/10.1016/j.marpetgeo.2015.07.030

Wallmann, K., Riedel, M., Hong, W. L., Patton, H., Hubbard, A., Pape, T., et al. (2018). Gas hydrate dissociation off Svalbard induced by isostatic rebound rather than global warming. Nature Communications, 9(1), 83. https://doi.org/10.1038/s41467-01702550-9

Westbrook, G. K., Thatcher, K. E., Rohling, E. J., Piotrowski, A. M., Pälike, H., Osborne, A. H., et al. (2009). Escape of methane gas from the seabed along the West Spitsbergen continental margin. Geophysical Research Letters, 36(15), L15608. https://doi.org/10.1029/2009GL039191

Yamamoto, A., Yamanaka, Y., Oka, A., \& Abe-Ouchi, A. (2014). Ocean oxygen depletion due to decomposition of submarine methane hydrate. Geophysical Research Letters, 41(14), 2014GL060483. https://doi.org/10.1002/2014GL060483 


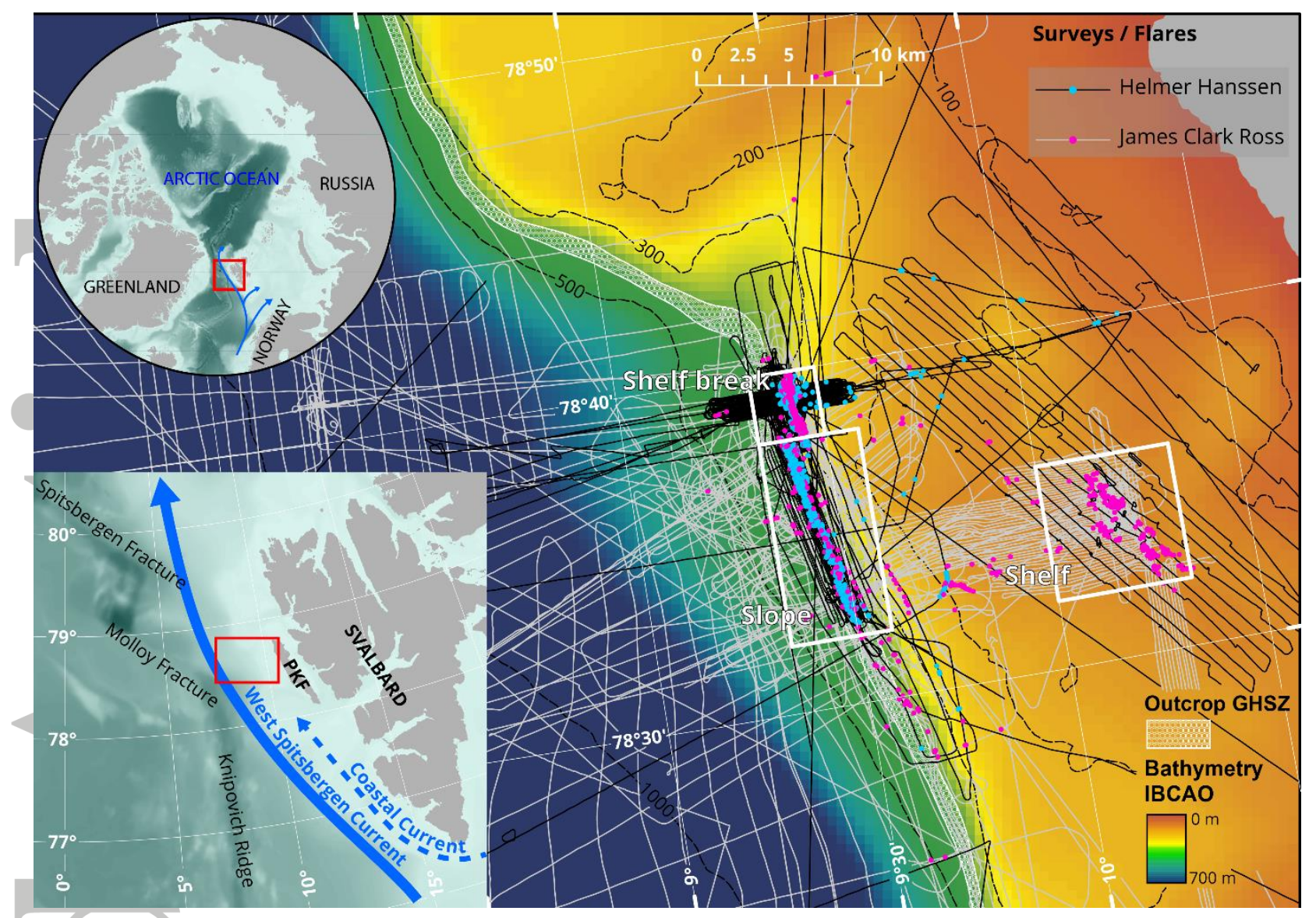

Figure 1. Bathymetric map of the study area. Black tracks with blue flare locations mark RVHH surveys and grey tracks with pink flare locations mark RRSJCR surveys. White hex pattern marks migration of the LGHZ (360-410 m isobaths; Westbrook et al., 2009). WSC, West Spitsbergen Current; CC, Coastal Current; PKF, Prins Karls Forland. Rectangles indicate the different survey areas.

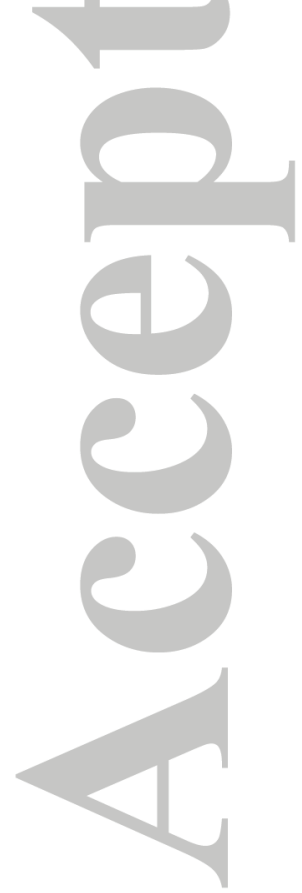

(C) 2019 American Geophysical Union. All rights reserved. 

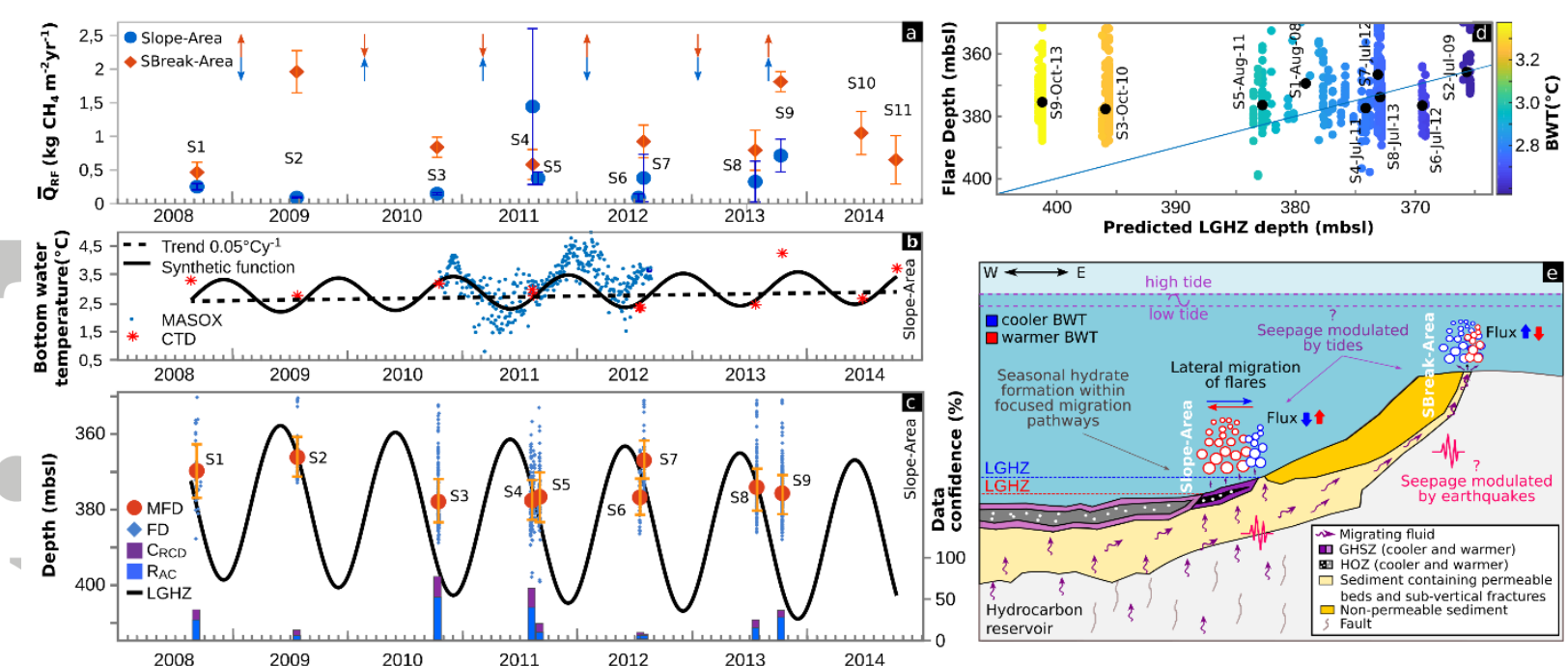

Figure 2. a) Temporal variability of $\mathrm{CH}_{4}$ fluxes in SBreak-Area and Slope-Area derived with the CAF method using BRSM M1C. Blue dots and orange diamonds represent mean $Q_{R F} \mathrm{~s}$ for the Slope-Area and SBreak-Area respectively; error bars show the standard deviation of fluxes from common areas used to calculate the mean $Q_{R F}$. Blue and orange arrows indicate changes in fluxes between surveys for the Slope-Area and SBreak-Area respectively. b) Time series of BWTs. The red stars indicate BWTs from CTD information and from the World Ocean Database and the blue dots show digitized values of mean BWTs per day, extracted from Berndt et al (2014). The black dashed line depicts the $0.05{ }^{\circ} \mathrm{C}$ yearly increase in BWT observed by Ferré et al. (2012), while the black continuous line represents the synthetic BWTs described in the text. c) Time series of Flare depths (FDs) and mean flare depths (MFDs), for flares located between 350 and 400 mbsl at the Slope-Area. Blue dots indicate individual flares, while the red dots with error bars indicate the mean depth and the corresponding standard deviation for each survey. Black line indicates the expected depth of the LGHZ, derived from the synthetic BWT function. Blue and violet bars indicate the confidence parameters $R_{A C}$ and $C_{R C D}$, described in section 2.5. d) Observed flare depths (FDs) vs predicted depth of the LGHZ. Small dots indicate individual flares (in total 1016 flares), colored by the synthetic BWT. Black dots indicate the mean flare depths (MFDs) for each of the surveys. Blue line depicts a perfect 1:1 relation between FD/MFD and the predicted LGHZ depth. e) Conceptual model of bubble seepage offshore PKF, illustrating the suggested flux changes in the Slope-Area and SBreak-Area, the spatial shift of bubble seepage, and the lateral migration of the LGHZ and the hydrate occurrence zone (HOZ) during cooler and warmer bottom water temperatures. The image also indicates the suggested interconnectivity between Slope-Area and SBreak-Area (light yellow patch and curved arrows). Earthquakes and tides are proposed as plausible control mechanisms of bubble seepage.

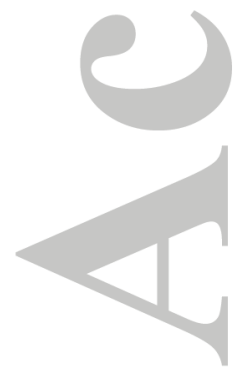


Table 1. Volumetric and mass flow rates of $\mathrm{CH}_{4}$ calculated using merged hydroacoustic information of SBreak-Area, Slope-Area, and Shelf-Area using different BRSM's (SI, Figure SI5; M1C: "Leifer" clean; M2C: "Mendelson" clean; M3C: "Leifer \& Patro" clean; M1D:"Leifer" clean; M2D: "Leifer \& Patro" dirty; M3D: "Woolf93"; M4D: "Thorpe 91" dirty).

Clean bubble models

\section{SBreak-Area}

Flow-rate, volumetric $\left(1 \mathrm{~min}^{-1}\right)$

Flow-rate mass $\left(\mathbf{t ~}^{-1}\right)$

Area with acoustic data $\left[\mathbf{m}^{2}\right]$

Mean annual flow-rate $\left[t \mathbf{y}^{-1}\right]$

Standard deviation flow-rate BRSM $\left[\mathrm{t} \mathrm{y}^{-1}\right]$

* Relative standard deviation flow-rate BRSM [\%]

Slope-Area

Flow-rate, volumetric $\left(1 \mathrm{~min}^{-1}\right)$

Flow-rate mass $\left(t^{-1}\right)$

Area with acoustic data $\left[\mathrm{m}^{2}\right]$

Mean annual flow-rate $\left[t \mathbf{y}^{-1}\right]$

Standard deviation flow-rate BRSM $\left[t \mathbf{y}^{-1}\right]$

*Relative standard deviation flow-rate BRSM [\%]

Shelf-Area

Flow-rate, volumetric $\left(1 \mathrm{~min}^{-1}\right)$

Flow-rate mass $\left(t^{-1}\right)$

Area with acoustic data $\left[\mathrm{m}^{2}\right]$

Mean annual flow-rate [t $\left.y^{-1}\right]$

Standard deviation flow-rate BRSM $\left[\mathbf{t y}^{-1}\right]$

*Relative standard deviation flow-rate BRSM [\%]

\begin{tabular}{|c|c|c|c|c|c|c|}
\hline & \\
\hline M1C & M2C & M3C & M1D & M2D & M3D & M4D \\
\hline 30.74 & 39.57 & 30.74 & 25.33 & 31.73 & 39.60 & 34.08 \\
\hline 258.01 & 332.14 & 258.01 & 212.60 & 266.30 & 332.38 & 286.08 \\
\hline & & & 646,234 & & & \\
\hline & 306.13 & & \multicolumn{4}{|c|}{274.34} \\
\hline & 41.72 & & \multicolumn{4}{|c|}{49.61} \\
\hline & \pm 13.63 & & \multicolumn{4}{|c|}{ \pm 18.08} \\
\hline M1C & M2C & M3C & M1D & M2D & M3D & M4D \\
\hline 37.62 & 48.79 & 48.23 & 31.00 & 39.12 & 48.82 & 42.02 \\
\hline 487.31 & 632.07 & 624.76 & 401.56 & 506.69 & 632.42 & 544.33 \\
\hline & & & 1466,867 & & & \\
\hline & 581.38 & & \multicolumn{4}{|c|}{521.25} \\
\hline & 81.55 & & \multicolumn{4}{|c|}{95.62} \\
\hline & \pm 14.03 & & \multicolumn{4}{|c|}{ \pm 18.34} \\
\hline M1C & M2C & M3C & M1D & M2D & M3D & M4D \\
\hline 15.20 & 19.63 & 19.40 & 12.53 & 15.74 & 19.65 & 16.91 \\
\hline 138.99 & 179.62 & 177.53 & 114.53 & 144.00 & 179.74 & 154.71 \\
\hline \multicolumn{7}{|c|}{507,447} \\
\hline & 165.38 & & \multicolumn{4}{|c|}{148.24} \\
\hline & 22.88 & & \multicolumn{4}{|c|}{27.01} \\
\hline & \pm 13.84 & & \multicolumn{4}{|c|}{ \pm 18.22} \\
\hline
\end{tabular}

*Relative standard deviation $=\frac{\sigma}{\bar{x}} \times 100 ; \sigma$ :standard deviation; $\bar{x}$ :mean 